\title{
Coronary Heart Disease Clinical Manifestation and Risk Factors in Japanese Immigrants and their Descendents in the City of São Paulo
}

\author{
Reynaldo Vicente Amato, Luiz Antonio Machado César, Antonio de Pádua Mansur, \\ W hady Armindo Hueb, José Renato Martines Martins, Caio de Brito Vianna, \\ José Antonio Franchini Ramires
}

São Paulo, SP - Brazil

\begin{abstract}
Objective - To assess whether a difference exists in coronary heart disease clinical manifestations and the prevalence of risk factors between Japanese immigrants and their descendents in the city of São Paulo.

Methods - Retrospective analysis of coronary artery disease clinical manifestations and the prevalence of risk factors, comparing 128 Japanese immigrants (Japanese group) with 304 Japanese descendents (Nisei group).

Results - The initial manifestation of the disease was earlier in the Nisei group (mean $=53$ years), a difference of 12 years when compared with that in the Japanese group (mean $=65$ years $)(P<0.001)$. Myocardial infarction was the first manifestation in both groups $(P=0.83)$. The following parameters were independently associated with early coronary events: smoking $(O R=2.25 ; 95 \% C I=$ $1.35-3.77 ; P<0.002)$; Nisei group $(O R=10.22 ; 95 \% C I=$ 5.64-18.5; $P<0.001)$; and female $\operatorname{sex}(\mathrm{OR}=5.04 ; 95 \% \mathrm{CI}=$ 2.66-9.52; $P<0.001)$.
\end{abstract}

Conclusion - The clinical presentation of coronary heart disease in the Japanese and their descendents in the city of São Paulo was similar, but coronary heart disease onset occurred approximately 12 years earlier in the Nisei group than in the Japanese group.

Keywords: coronary heart disease, diabetes mellitus, hypercholesterolemia, hypertriglyceridemia, systemic arterial hypertension

Instituto do Coração of the Hospital das Clínicas (InCor) of the FMUSP Mailing address: Reynaldo Vicente Amato - InCor - Unidade Clínica de Coronariopatia Crônica - Divisão Clínica - Av. Dr. Eneas C. Aguiar, 44 - 05403000 - São Paulo, Brazil - E-mail: dcllucesar@incor.usp.br English version by Stela Maris C. e Gandour

Received - 10/29/02

Accepted - 12/02/02
Immigration of large population groups to regions with characteristics different from those of their places of origin allows the study of biological and psychosocial changes occurring through the interaction of these groups with the new environments ${ }^{1}$. Several studies on Japanese immigrants in the United States of America have placed mortality due to cardiac disease in Nisei individuals of California and Hawaii at an intermediate level between that observed in Japan and that of the North American population of Caucasian heritage. From 1965 onwards, the Ni-Hon-San study ${ }^{2}$ compared the differences of cardiovascular disease between Japanese males aged from 45 to 69 years living in Japan (Hiroshima and Nagasaki) and groups of Japanese immigrants living in California and Hawaii. Of the latter, approximately $40 \%$ had originally come from Hiroshima and the southwestern region of Japan, which provided similar genetic patterns in the 3 cohorts ${ }^{3}$. Compared with the Japanese cohort, the Californian and Hawaiian cohorts had a greater prevalence and incidence of coronary heart disease and a greater prevalence of risk factors for that disease ${ }^{4}$. Mortality due to coronary heart disease was also greater in the Californian and Hawaiian groups ${ }^{2-6}$, which, in addition, also had a greater incidence of myocardial infarction as compared with that of the Japanese group living in Japan ${ }^{7}$. In our country, as in the United States, 2 waves of Japanese immigration occurred as follows: from 1908 to $1933,110,191$ individuals, and from 1950 to 1959 , approximately 34,266 individuals. In Brazil, the Japanese immigrants concentrated in the southern and southeastern regions, mainly in the State of São Paulo, which has the largest Japanese community in Brazil, estimated at 1,400,000 inhabitants, 326,000 of whom live in the municipality of São Paulo ${ }^{8}$. In regard to coronary heart disease in immigrants, an intermediate mortality rate between those of the Japanese and the population of São Paulo was observed ${ }^{9,10}$. Similar values were reported in a rural population in the Brazilian State of Paraná ${ }^{11}$. The risk 
factors for coronary heart disease were also greater in Japanese descendents in the city of Campo Grande in the Brazilian State of Mato Grosso do Sul as compared with those of the Japanese who founded that colony ${ }^{12}$. The objective of this study was to evaluate whether differences exist in the clinical presentation of coronary heart disease and the prevalence of its risk factors between the Japanese immigrants and their descendents in the city of São Paulo.

\section{Methods}

Patients of Japanese origin who sought medical care in the outpatient clinics of the Chronic Coronary Heart Disease Clinical Unit of the Instituto do Coração of the Medical School of the University of São Paulo were retrospectively studied. A total of 432 Japanese and Japanese descendents were selected through information obtained from their medical records considering ethnicity, family name, place of birth, and name of parents. Those patients had sought the outpatient clinics from July 1977 to April 1998 and had been clinically and angiographically diagnosed with coronary heart disease. After selection through the medical records, the patients were divided into 2 groups as follows: Japanese group - comprising the individuals who had been born in Japan and immigrated to Brazil; and the Nisei group - comprising the Brazilian children of those Japanese. The Japanese group comprised 128 patients, 82 males and 46 females. The Nisei group comprised 304 patients, 80 females and 224 males. Data were then collected and the following variables of interest for the comparative study were obtained: sex, nationality, date, and age of the patients on the day of the first ambulatory consultation. The age at which coronary heart disease began was determined by the first event or its first suggestive manifestation, either characterized by angina pectoris or myocardial infarction ${ }^{13,14}$. The cases with the associated diagnosis of valvular heart diseases and those with no clinical diagnosis of coronary heart disease were excluded. For the electrocardiographic diagnosis of myocardial infarction and silent ischemia on stress electrocardiography, the classical criteria ${ }^{15,16}$ were applied to data referring to the first medical consultation or first coronary event.

The following variables of clinical history and laboratory findings were chosen for analysis: 1) familial antecedents, considering the report of sudden death or myocardial infarction among the parents or first-degree relatives before the age of 55 years for males and 65 years for females ${ }^{17-1} ; 2$ ) body mass index obtained according to the formula BMI $=$ weight $/(\text { height })^{2}$, values between 18.0 and 24.9 $\mathrm{kg} / \mathrm{m}^{2}$ being considered normal ${ }^{20} ; 3$ ) smoking, when present at the time of the initial consultation and independent of the amount of cigarettes smoked per day and the duration of the smoking habit; 4) diastolic (DBP) and systolic (SBP) blood pressures obtained on the day of the first consultation and considering the borderline values of normality (normal systolic blood pressure $139 \mathrm{mmHg}$ and normal diastolic blood pressure $89 \mathrm{mmHg}^{21}$ ); 5) diabetes mellitus, reported by the patient on the first consultation or the presence of a high glycemia value $(\geq 126 \mathrm{mg} / \mathrm{dL}$, with the normal range between 70 and 110) ${ }^{22,23}$; and 6) cholesterolemia and triglyceridemia related to the first consultation, with normal values established as $<200 \mathrm{mg} / \mathrm{dL}$ and $<150 \mathrm{mg} / \mathrm{dL}$, respectively ${ }^{24}$.

The numeric variables were analyzed with the Student $t$ test, $\mathrm{P}<0.05$ being the significance level adopted. For the nonnumerical variables, the chi-square test or the Fisher exact test was used with the same significance level $(\mathrm{P}<$ $0.05)^{25}$. After the comparative analysis between the groups, and considering that the result obtained was a lower mean age for the initial manifestation of coronary heart disease in the Nisei group, we considered it appropriate to complement our study with the analysis of the variables that could be influencing this finding. To know the effect of all variables on the clinical presentation of coronary heart disease in the 2 groups using the technique of logistic regression ${ }^{26}$ as a predictive model of analysis, a dependent variable, the early coronary event, was established. An early coronary event was defined as the appearance of coronary heart disease before the age of 55 years for males and 65 years for females. This way and with this criterion established, the patients were separated into 2 groups according to the presence or absence of an early coronary event. Then, through univariate analysis and with the same level of significance adopted, the early coronary event variable and the numerical and nonnumerical variables were compared. The variables that proved significant were submitted to the multivariate approach model. Finally, with the latter variables, ie, those with statistical significance, an odds ratio was calculated for each factor.

\section{Result}

Table I shows the distribution of the patients in the groups according to sex. The proportion of females in the Japanese group (36\%) was greater than that in the Nisei group $(26 \%)$, and this difference was significant $(\mathrm{P}=0.045)$. Table II shows that the difference between the mean ages of coronary heart disease onset in the Nisei and in the Japanese groups was at least 10 years, both for males and females. Figures 1 and 2 depict the distribution of the age of coronary heart disease onset in the groups. The overall mean age of coronary heart disease manifestation was 12 years earlier in the Nisei group. In the curve for accumulated distribution of ages, the greater incline of the curve represen-

\begin{tabular}{|lccc|}
\hline \multicolumn{4}{|c|}{ Table I - Sex distribution in the Japanese and Nisei groups } \\
\hline \multirow{2}{*}{ Group } & Males & Females \\
\hline \multirow{2}{*}{ Japanese } & Number & 82 & 46 \\
\multirow{2}{*}{ Nisei } & Proportion & $64 \%$ & $36 \%$ \\
& Number & 224 & 80 \\
& Proportion & $74 \%$ & $26 \%$ \\
\hline \multirow{2}{*}{ Chi-square test, $\mathrm{P}=0.04}$. & & \\
\hline
\end{tabular}


ting the Nisei group represents a greater number of patients with early manifestations of coronary heart disease than in the Japanese group. Table III shows the initial coronary heart disease event. No difference was observed in the clinical presentation of the disease between the 2 groups.

The distribution of risk factors, which were considered variables of analysis in the 2 groups, is shown in table IV. Because some variables were not available in all medical records, the analysis was carried out with different numbers

\begin{tabular}{|c|c|c|c|}
\hline \multicolumn{4}{|c|}{$\begin{array}{c}\text { Table II - Distribution of the quartiles and age of coronary disease } \\
\text { onset (in years) in the Japanese and Nisei groups } \\
\text { according to sex }\end{array}$} \\
\hline & \multirow[t]{2}{*}{ Quartiles } & \multicolumn{2}{|c|}{ Age } \\
\hline & & Japanese & Nisei \\
\hline \multirow[t]{8}{*}{ Males } & Minimum & 40 & 32 \\
\hline & Quartile $25 \%$ & 56 & 45 \\
\hline & Median $(50 \%)$ & 64 & 52 \\
\hline & Quartile $75 \%$ & 71.3 & 58 \\
\hline & Maximum & 84 & 85 \\
\hline & Mean & 63.6 & 52.7 \\
\hline & Mean Standard Error & 1.04 & 0.59 \\
\hline & Number & 82 & 223 \\
\hline \multirow[t]{9}{*}{ Females } & Minimum & 48 & 39 \\
\hline & Quartile 25\% & 63 & 52 \\
\hline & Median (50\%) & 70 & 56 \\
\hline & Quartile $75 \%$ & 75.5 & 62.8 \\
\hline & Maximum & 85 & 74 \\
\hline & Mean & 68.7 & 56.6 \\
\hline & Mean Standard Error & 1.3 & 0.91 \\
\hline & Number & 45 & 80 \\
\hline & Minimum & 40 & 32 \\
\hline
\end{tabular}

\begin{tabular}{|lcc|}
\hline \multicolumn{3}{|c|}{ Table III $-\begin{array}{c}\text { Initial coronary heart disease event in the } \\
\text { Japanese and Nisei groups }\end{array}$} \\
\hline Initial event & Japanese $\mathrm{n}=128(\%)$ & Nisei $\mathrm{n}=304(\%)$ \\
\hline Stable angina & $61(48)$ & $129(42)$ \\
Unstable angina & $21(16)$ & $63(21)$ \\
Myocardial infarction & $46(36)$ & $111(36)$ \\
\hline Fisher exact test, $\mathrm{P}=0.835$. & \\
\hline
\end{tabular}

\begin{tabular}{|lrrr|}
\hline \multicolumn{3}{|c|}{$\begin{array}{c}\text { Table IV - Distribution of the percentages and mean values of } \\
\text { risk factors for coronary heart disease in the Japanese } \\
\text { and Nisei groups }\end{array}$} \\
\hline Risk factors & Japanese & Nisei & P value \\
\hline Familial antecedents & $33 \%$ & $37 \%$ & 0.45 \\
Diabetes mellitus & $45 \%$ & $45 \%$ & 0.97 \\
Active smoking & $36 \%$ & $48 \%$ & 0.04 \\
Body mass index* & 24.7 & 25.9 & 0.002 \\
Systolic blood pressure** & 141.5 & 138.8 & 0.29 \\
Diastolic blood pressure** & 85.6 & 87 & 0.35 \\
Glycemia* & 126 & 128.4 & 0.62 \\
Cholesterolemia* & 223.9 & 233.9 & 0.11 \\
Triglyceridemia* & 243.8 & 261.4 & 0.56 \\
\hline * values in $\mathrm{kg} / \mathrm{m}^{2}, * *$ values in $\mathrm{mmHg}, * * *$ \\
\hline
\end{tabular}

for each variable: familial antecedents, 329 cases; diabetes mellitus, 428; active smoking, 369; body mass index, 413; systolic and diastolic blood pressures, 425; glycemia, 420; cholesterolemia and triglyceridemia, 348 .

Table $\mathrm{V}$ shows the results and the odds ratio for each factor. In regard to statistically significant variables, with smoking, on average, a 2.25-fold greater probability existed for the occurrence of an early coronary event. Being Nisei had a 10.2-fold greater probability of an early coronary event than did being Japanese; likewise, being female had a 5 -fold greater probability of an early coronary event than that of being male.

\section{Discussion}

Our results showed that coronary heart disease appeared approximately 1 decade earlier in the Nisei group, which had a 10 -fold greater probability of an early coronary event than did the Japanese group. This temporal difference in the clinical presentation of coronary heart disease may be attributed to the greater degree of acculturation reached by the descendents of the Japanese in São Paulo, resulting in the greater prevalence of the risk factors for coronary heart disease in that population. The studies on acculturation of Japanese groups in California ${ }^{27,29}$ and Hawaii ${ }^{29}$, showing that the patients with a greater degree of acculturation have a greater prevalence and incidence of coronary heart disease, corroborate our assertion. The initial manifestation of coronary heart disease in the 2 groups was similar and comprised angina pectoris and myocardial infarction, and only 1 patient was diagnosed with silent ischemia. Considering that the Nisei group had a greater degree of acculturation, and according to the results found in the Californian ${ }^{27,29}$ and Hawaiian ${ }^{29}$ studies, and in the study by Mizushima et al ${ }^{12}$, we might have expected a greater prevalence of angina or myocardial infarction in the Nisei group and also in the Japanese and their descendents in Campo Grande and São Paulo. These differences regarding the results of prevalence between ours and that of the other studies may be explained by the fact that, in our study, the prevalence considered was that at the moment of the initial manifestation of the disease.

The results of the Ni-Hon-San study ${ }^{2}$ showed a greater prevalence of smoking in the Japan group (75\%) as compared with the Hawaii (44\%) and the California (35\%) groups. That study also found that, among Japanese, a greater consumption of cigarettes per day was not associated with an increa-

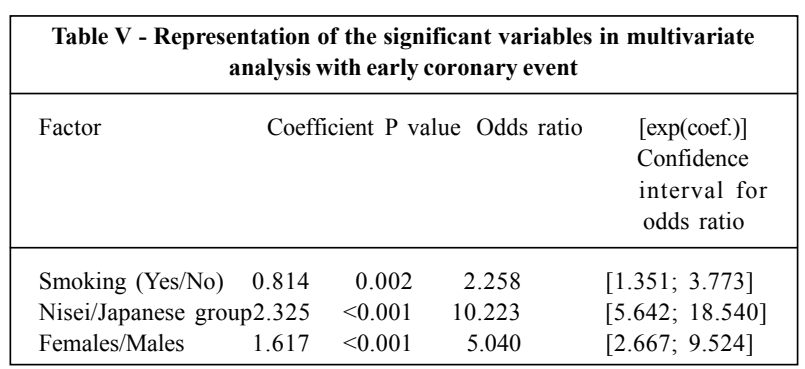




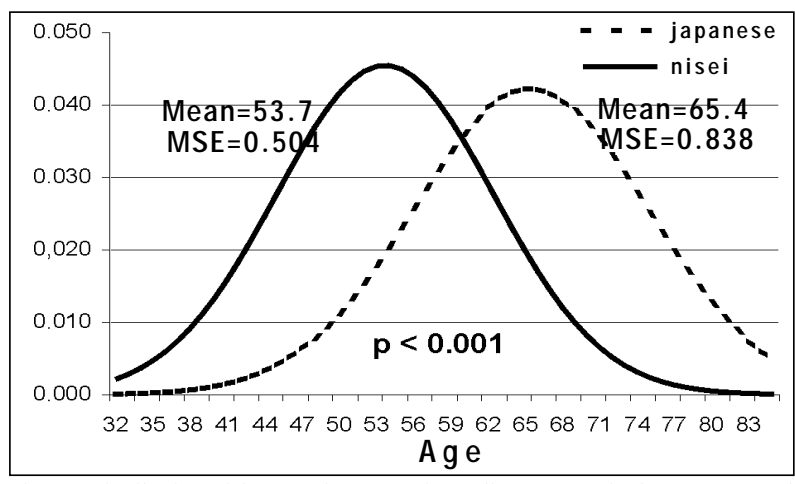

Fig. 1 - Distribution of the age of coronary heart disease onset in the Japanese and Nisei groups.

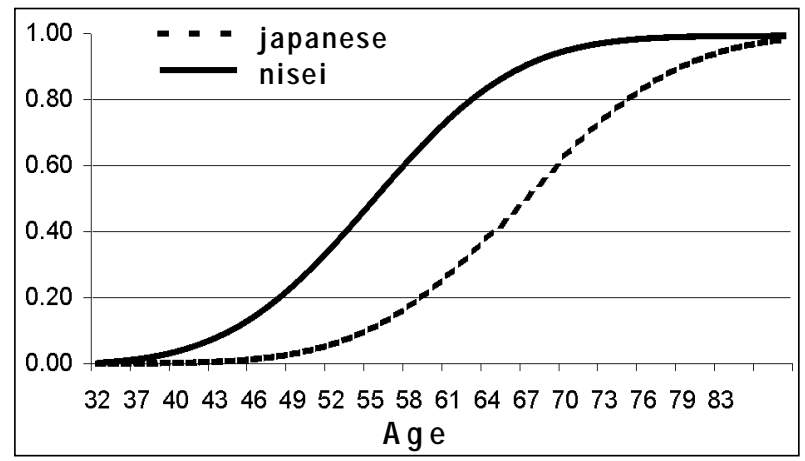

Fig. 2 - Accumulated distribution of the age of coronary heart disease onset in the Japanese and Nisei groups.

se in the incidence of coronary heart disease; on the other hand, in the Hawaiian group, smoking was an important risk factor for coronary heart disease ${ }^{28,30,31}$. In the study by Mizushima et al ${ }^{12}$, the Japanese group also had a greater prevalence of smoking. On the other hand, our findings showed a significant proportion of smokers in the Nisei group. The greater prevalence of smoking in the Nisei group and the greater probability of occurrence of an early coronary event in smokers in our study contributed towards making smoking an important risk factor for coronary heart disease among Nisei. The greater prevalence of hypercholesterolemia, hypertriglyceridemia, and a greater body mass index in the Nisei group agreed with the findings of Reed et al ${ }^{28}$ in comparing the already acculturated Japanese immigrants in Hawaii and California with the individuals in the Japan group ${ }^{4}$. They reflect the greater consumption of unsaturated fat and a larger amount of animal protein by the $\mathrm{Nisei}^{32}$, also reported by Car- doso et $\mathrm{al}^{33}$ in a study about dietary patterns in the Nisei population of São Paulo. In regard to glycemia, our patients had extremely elevated mean values $(>125 \mathrm{mg} / \mathrm{dL}$ in both groups), a large number of patients having values above those of the normal limit (around 50\%), but with no difference between the 2 groups. Likewise, an increased incidence (45\%) of diabetes mellitus was found in both groups. The prevalence of hyperglycemia in the Ni-Hon-San study ${ }^{2}$, both in Hawaii and California, is similar and greater than that observed in Japan ${ }^{4}$, but lower than that observed in our study. Ferreira et $\mathrm{ll}^{34}$, studying the population of the Brazilian city of Bauru, reported overall prevalence values of noninsulin-dependent diabetes mellitus of $12 \%$ in the Japanese group and $16 \%$ in the Nisei group. A study carried out in Brazi $1{ }^{35}$ reported a greater prevalence of diabetes mellitus $(17 \%)$ in coronary patients as compared with that in the general population. That value is greater than the prevalence of diabetes $(7 \%)$ and glucose intolerance (7\%) found in the urban Brazilian population ${ }^{36}$. The greater intake of noncomplex carbohydrates may be a cause of that finding, as it has been used to explain hyperglycemia in those patients ${ }^{32}$. The proportion of our patients with increased body mass index, more than $37 \%$ of the cases, may justify our findings but not such an elevated percentage of diabetes mellitus. Another explanation may be the greater glucose intolerance observed in patients with metabolic syndrome ${ }^{37}$. Therefore, diabetes mellitus should be carefully considered an important risk factor for coronary heart disease in the Japanese and their descendents in Brazil. In another analysis of the Ni-Hon-San study ${ }^{38}$, greater blood pressure levels were found in the $\mathrm{Ca}$ lifornian cohort than in the Japanese cohort; the values in the Hawaiian cohort occupy an intermediary position, the increase in blood pressure relating to the increase in body weight. These findings are similar to those of Mizushima et al ${ }^{12}$. In our study, both groups had similar mean systolic and diastolic blood pressures, and the proportions of patients with systolic and diastolic blood pressures considered elevated were also similar in both groups.

Finally, our study comprised a population that sought medical care at our institution. Considering the period from 1977 to 1998 and the number of patients studied, our results do certainly provide information regarding these 2 groups, the Japanese and their descendents, mainly in regard to the difference in the age of coronary heart disease onset for the same degree of coronary impairment.

\section{References}

1. Franco L. Diabetes in japanese - brazilians - influence of the acculturation process. Diabetes Res Clin Prac 1996;34:51-7.

2. Syme LS, Marmot MG, Kagan A, et al. Epidemiologic studies of coronary heart disease and stroke in japanese men living in Japan, Havaii and California : introduction. Am J Epidemiol 1975;102:514-25.

3. Benfante R. Studies of cardiovascular disease and cause-specific mortality trends in japanese-american men living in Havaii and risk factor comparisons with other japanese populations in the Pacific region: a review. Human Biology 1992;64:791-805

4. Marmot MG, Syme LS, Kagan A, et al. Epidemiologic studies of coronary heart disease and stroke in japanese men living in Japan, Havaii and California: prevalence of coronary heart and hypertensive heart disease and associated risk factors. Am J Epidemiol 1975;102:514-25.

5. Worth RM, Kato H, Rhoads GG, et al. Epidemiologic studies of coronary heart 
disease and stroke in japanese men living in Japan, Hawaii and California : mortality. Am J Epidemiol 1975;102:481-90.

6. Yano K, MacLean CJ, Reed DM. Comparison of the 12-year mortality and predictive factors of coronary heart disease among japanese men in Japan and Hawaii. Am J Epidemiol 1988;127:476-87.

7. Robertson TL, Kato H, Rhoads GG, et al. Epidemiologic studies of coronary heart disease and stroke in japanese men living in Japan, Havaii and California: incidence of myocardial infarction and death from coronary heart disease. Am J Cardiol 1977;39:239-43.

8. Brasil: 500 anos de Povoamento, Rio de Janeiro. Apêndice: Estatísticas de 500 anos de Povoamento IBGE.2000; 226.

9. Tsugane S, Gotlieb SLD, Laurenti R, et al. Mortality and cause of death among first-generation japanese in São Paulo, Brazil. Internat J Epidemiol 1989; 18:647-51.

10. Gotlieb SLD. Mortalidade em migrantes japoneses residentes no município de São Paulo, Brasil, 1980. Rev Saúde Públ 1990;24:453-67.

11. Souza RKT, Gothieb SL.D. Mortalidade em migrantes japoneses residentes no Paraná, Brasil. Rev Saúde Públ 1999;33:262-72.

12. Mizushima S, Moriguchi EH, Ishikawa $\mathrm{P}$, et al. Fish intake and cardiovascular risk among middle-aged japanese in Japan and Brazil. J Cardiovasc Risk 1997;4:191-99.

13. Guidelines for the management of patients with chronic stable angina: a report of the American College of Cardiology/American Heart Association task force on practice with chronic stable angina. J Am Coll Cardiol 1999;33:2092-197.

14. Guidelines for the management of patients with unstable angina/non ST segment elevation myocardial infarction: a report of the American College of Cardiology/ American Heart Association task force on practice guidelines (Committee on the management of patients with unstable angina). J Am Coll Cardiol 2000;36:9701062 .

15. Ramires JAF, OliveiraAS. Eletrocardiograma Normal e Patológico. coordenação Paulo Jorge Moffa, Paulo César R. Sanches. $7^{a}$ ed. São Paulo, Roca (Série Incor): 2001.

16. Consenso Nacional de Ergometria. Arq Bras Cardiol 1995;65:189-211.

17. National cholesterol education program. Second report of expert panel on detection, evaluation, and treatment of high blood cholesterol in adults (Adult treatment panel II). Circulation 1994;89:1333-45.

18. Barret-Connor E, Khaw K. Family history of heart attack as an independent predictor of death due to cardiovascular disease. Circulation 1984;69:1065-84

19. Colditz GA, Rimm EB, Giovannucci E, et al. A prospective study of parenta history of myocardial infarction and coronary artery disease in men. Am. J. Cardiol 1991;67:933-38.

20. National Heart, Lung, and Blood Institute/National Institutes of Diabetes and Digestive and Kidney Diseases. Clinical Guidelines on the Identification, Evaluation and Treatment of Overweight and Obesity in Adults: the Evidence Report. Bethesda : National Institutes of Health 1998;1-128.

21. Consenso Brasileiro de Hipertensão Arterial (III). Rev Bras Clin Terap 1998;24:231-72.
22. Report of the expert committee on the diagnosis and classification of diabetes mellitus. Diabetes Care 2000;23:4-19.

23. Gross JL, Ferreira SRG, Franco L.J, et al. Diagnóstico e classificação do diabetes mellitus tipo 2. Recomendações da Sociedade Brasileira de Diabetes. Arq Bras Endocrinol Metab 2000;44:5-32.

24. Diretrizes Brasileiras sobre Dislipidemias ( III ). Diretriz de Prevenção da Aterosclerose. Departamento de Aterosclerose da Sociedade Brasileira de Cardiologia. Arq Bras Cardiol 2001;77:1-48

25. Arnitage P, Berry G. Statistical Methods in Medical Research. $3^{\text {th }}$ ed. Oxford, Blackwell Science: 1994.

26. Hosmer DW, Lemeshow S. Applied Logistig Regression. New York: John Wiley \& Sons, 1989.

27. Marmot MG, Syme SL. Acculturation and coronary heart disease in JapaneseAmericans. Am J Epidemiol 1976;104:225-47.

28. Reed D, McGee D, Cohen J, et al. Acculturation and coronary heart disease among japanese men in Havaii. Am J Epidemiol 1982;115:894-905.

29. Yano K, Blackwelder WC, Kagan A et al. Childhood cultural experience and incidence of coronary heart disease in Hawaii Japanese men. Am J Epidemiol 1979;109:440-50.

30. Robertson TL, Kato H, Rhoads GG, et al. Epidemiologic studies of coronary heart disease and stroke in japanese men living in Japan, Havaii and California: coronary heart disease risk factors in Japan and Havaii. Am J Cardiol 1977 b;39:244-49.

31. Yano K, Reed DM, McGee DL. Ten-year incidence of coronary heart disease in Honolulu Heart Program: relationship to biologic and lifestyle characteristics. Am J Epidemiol 1984;119:653-66.

32. Kagan A, Harris BR, Winkelstein W, et al. Epidemiologic studies of coronary heart disease and stroke in Japanese men living in Japan, Hawaii, and California: demografic, physical, dietary and biochemical characteristics. J Chronic Dis 1974;27:345-64

33. Cardoso MA, Hamada GS, Souza JM, et al. Dietary patterns in japanese migrants to southestern Brasil and their descendants. J. Epidemiol 1997;7:198-204.

34. Ferreira SRG, Iunes M, Franco LJ, et al. The Japanese-Brasilian Diabetes Study Grroup. Disturbances of glucose and lipid metabolism in first and second generation japanese - brazilians. Diabetes Res Clin Prac 1996;34:59-63.

35. MansurA.P, MattarA.PL, Tsubo CE et al. Prescrição e aderência das estatinas em pacientes com doença arterial coronariana e hipercolesterolemia. Arq Bras Cardiol 2001;76:111-4.

36. Malerbi DA, Franco LJ. Multicenter study of the prevalence of diabetes mellitus and impaired glucose tolerance in the urban brazilian population aged 30-69 yr. The Brazilian Cooperative Group on the Study of Diabetes Prevalence. Diabetes Care 1992;15:1509-16.

37. Lerario DDG, Gimeno SG, Franco L.J, et al. Grupo de estudos de diabetes na comunidade nipo-brasileira, São Paulo, SP Brasil. Excesso de peso e gordura abdominal a síndrome metabólica em nipo-brasileiros. Rev Saúde Públ 2002;36:4-11.

38. Winkelstein WJR, Kagan A, Kato H, et al. Epidemiologic studies of coronary heart disease and stroke in japanese men living in Japan, Havaii and California: blood pressure distributions. Am J Epidemiol 1975;102:502-13. 